14th International Symposium for the Advancement of Boundary Layer Remote Sensing IOP Publishing IOP Conf. Series: Earth and Environmental Science 1 (2008) 012055 doi:10.1088/1755-1307/1/1/012055

\title{
Emission rates with the boundary layer budget method supported by acoustic remote sensing
}

\author{
S Emeis \\ Institut für Meteorologie und Klimaforschung - Atmosphärische Umweltforschung, \\ Forschungszentrum Karlsruhe, Garmisch-Partenkirchen, Germany \\ stefan.emeis@imk.fzk.de
}

\begin{abstract}
Remote sensing can help to derive turbulent fluxes in the atmosphere even if the remote sensing technique used itself is not able to resolve turbulent fluctuations. Turbulent fluxes are important components of atmospheric energy and substance budgets and they play a dominant role in the surface-atmosphere exchange. Apart from high-resolution in situ measurements it is difficult to determine them. This paper presents an inverse method to derive a regionally-averaged vertical turbulent flux of methane from the surface into the atmospheric boundary layer. The determination of aggregated surface emission fluxes of methane from an agricultural area in Southern Germany on an intermediate scale between the local and the regional scale is based on using a boundary layer budget method combined with surface-based acoustic remote sensing of the mixing-layer height with a sodar. The order of magnitude of the resulting methane emission fluxes coincide well with the national methane emission inventory.
\end{abstract}

\section{Introduction}

The supervision of the emission rates of greenhouse gases has become an important task for all nations complying with the Kyoto Protocol. This task is difficult if the sources are not well-known or if the sources are diffuse without fixed boundaries. One method to derive such diffuse emission fluxes is to measure the concentration of the emitted substance in question upwind and downwind of the supposed emission source and then - afterwards - to calculate the emission source strength via an inverse (i.e. backward) dispersion modelling ([1], [2]).

If the diffuse emission takes place into a well-defined volume of air then the emission could be easily computed from the concentration increase within this air volume by a residual technique ([3], [4]). Such a well-defined air volume could be the air underneath a nocturnal near-surface inversion. The problem is then shifted to the task to monitor the height of this inversion. Here, remote sensing can be a good tool to do so ([5], [6], [7], [8]).

In principle, different methods are available for the remote sensing of the mixing-layer height and nocturnal inversions. In [8] and [9] the abilities of a sodar and a ceilometer have been demonstrated. Here, a sodar was available as remote sensing device to monitor the height of the nocturnal inversion. The methane concentrations have been measured by a near-by surface-based in-situ instrument. This paper will describe in more detail the residual technique and will show the feasibility of this remote sensing-based method with an example already sketched in [10]. Section 2 shortly introduces the data, section 3 presents the residual technique, and section 4 displays some results. 
14th International Symposium for the Advancement of Boundary Layer Remote Sensing IOP Publishing IOP Conf. Series: Earth and Environmental Science 1 (2008) $012055 \quad$ doi:10.1088/1755-1307/1/1/012055

\section{Data}

The data have been taken in the framework of the ICAROS NET project in May 2003 in Southern Germany. The ICAROS NET was designed to deliver mixing-layer height and air quality data for the intercomparison with satellite data (see [11] for an evaluation of the correlation between air pollution and mixing-layer height from this project). The methane concentrations have been measured with 30 min resolution by a HORIBA APHA-350E HC analysator in Maisach west of Munich in a few metres height above ground. The sodar was a three-antenna METEK DSDR3x7 Doppler sodar with a maximum range of $1300 \mathrm{~m}$ which was operated with $30 \mathrm{~m}$ vertical resolution and 10 minutes time resolution. The spatial distance between the two instruments was about $2 \mathrm{~km}$. The measurement site was an essentially flat rural area with a few isolated pieces of forest. Munich is situated about $25 \mathrm{~km}$ east of the site. Between the two instruments was the short-cut meadow of a no longer used military airfield.

\section{Principle of the residual method}

Let $e$ be an atmospheric property - here the concentration of the greenhouse gas methane - and $\vec{v}$ the vector of the three-dimensional motion, and let us denote the mean quantity by an overbar $\left({ }^{-}\right)$and the deviation from this mean by a prime ('). Then $\vec{e} \bar{e}$ is the mean flux of the property $e$ and $\overline{e^{\prime} v^{\prime}}$ the turbulent (sub-synoptic) flux of this property. The actual flux of the property $e$ therefore is the sum out of two parts:

$$
\overrightarrow{e v}=\overrightarrow{e v}+\overrightarrow{e^{\prime}} \overrightarrow{v^{\prime}}
$$

In areas - like those close to the lower boundary of the atmosphere - where mean vertical motions are negligible vertical transports of any property are completely governed by turbulent fluxes of this property. Basis of all residual techniques is the continuity equation for an atmospheric property e that has sources $\mathrm{Q}$ and/or sinks $\mathrm{R}$ in the volume of interest $\mathrm{V}$.

$$
\int_{V} \frac{\partial e}{\partial t} d V=-\int_{V} \nabla e \vec{v} d V+\int_{V} Q d V-\int_{V} R d V
$$

By the virtue of the Gauss theorem the first volume integral on the right-hand side of (2) can be replaced by an integral over the surface $\mathrm{S}$ surrounding this volume $\left(\mathrm{v}_{\mathrm{n}}\right.$ is the velocity component perpendicular to this surface).

$$
\int_{V} \nabla e \vec{v} d V=\int_{S} e v_{n} \cdot d S
$$

Following (1) we can rewrite the right-hand side of (3). Hereby we imply that the spatial dimensions over which the integrals are computed are much larger than the spatial scale designed by the overbar.

$$
\int_{S} e v_{n} d S=\int_{S}^{\bar{e}} \bar{e} v_{n} d S+\int_{S} \overline{e^{\prime} v_{n}^{\prime}} d S
$$

Putting (2) to (4) together we can solve for the integral over the turbulent fluxes $\overline{e^{\prime} v_{n}^{\prime}}$ through the surface enclosing the volume of interest: 


$$
\int_{S} \overline{e^{\prime} v_{n}^{\prime}} d S=-\int_{V} \frac{\partial e}{\partial t} d V-\int_{S}^{--} \overline{e v}_{n} d S+\int_{V} Q d V-\int_{V} R d V
$$

Neglecting horizontal turbulent fluxes, which are usually much smaller than their respective mean fluxes, denoting the vertical wind component by $w$ and introducing a surface flux $\overline{e^{\prime} w_{\text {surf }}^{\prime}}$ we get for the vertical turbulent flux through the horizontal surface $S_{1}$ at the top of the volume $V$ :

$$
\int_{S_{1}} \overline{e^{\prime} w^{\prime}} d S=-\int_{V} \frac{\partial e}{\partial t} d V-\int_{S} \bar{e} v_{n} d S-\int_{S_{\text {surf }}} \overline{e^{\prime} w^{\prime}} d S+\int_{V} Q d V-\int_{V} R d V
$$

\section{Determination of spatially aggregated surface fluxes}

Imagine now an atmospheric boundary layer over an area with inhomogeneous land use patterns, which is covered by a thermal inversion that suppresses all turbulent motions at the height of the inversion. In this case, the left-hand side of (6) would be zero. In this case equation (6) can be evaluated in a residual way ([3], [4]). If we further assume that horizontal advection can be neglected, then the second term on the right-hand side of (6) vanishes, too. The same applies to the fourth and the fifth term on the right-hand side if we stipulate the absence of any sources and sinks within the boundary-layer air. We then get:

$$
\int_{S_{\text {surf }}} \overline{e^{\prime} w^{\prime}} d S=-\int_{V} \frac{\partial e}{\partial t} d V
$$

This means that a spatially aggregated surface flux of a property $e$ into the atmospheric boundary layer can be determined from the increase of the density of $e$ within the boundary-layer air in a volume $V=S_{\text {surf }} \cdot z$ if the boundary layer is horizontally homogeneous in the respect that horizontal advection is negligible and if it is covered by an inversion in a known height $z$. Above the height $z$ we assume to have background concentrations of methane. If the inversion moves upward this would mean entrainment of air with this background concentration from above. We will evaluate (7) for the time from 10 p.m. to 6 a.m. During this time the inversion will be in its lowest position (see Fig. 2, especially in the night from 23 May to 24 May and the following one). Therefore we will neglect entrainment when evaluating Eq. (7) in this paper. A possible imbalance in Eq. (7) may be given by the measurement errors for the density of the property $e$ and the height of the volume $\mathrm{z}$, the correctness of the assumption of negligible horizontal advection, and the correctness of the assumption of perfect vertical mixing in the layer below the inversion. Probably the last point has the largest influence on the result. The absolute value of the methane concentration is not really important, only the nocturnal increase has been used. This increase is believed to be correct with a few percent. The precision of the height $z$ from the sodar data is limited by the vertical resolution used during the sodar operation. Thus the lowest height may be in error by up to $30 \%$. With increasing height $z$ this error decreases linearly. Therefore, finally, the methane surface flux values may be in error of about $50 \%$.

The algorithm used here for the determination of the mixing layer height $\mathrm{z}$ from sodar data ([7], [8]) searches for:

- the height of a turbulent layer (H1) characterised by high acoustic backscatter intensities R(z) due to thermal fluctuations (therefore having a high variance of the vertical velocity component $\sigma_{\mathrm{w}}$ ),

- several lifted inversions (H2_n) characterized by secondary maxima of acoustic backscatter due to a sharp increase of temperature with height and simultaneously low $\sigma_{\mathrm{w}}$, and 
- the height of a surface-based stable layer (H3) characterised by high backscatter intensities due to a large mean vertical temperature gradient starting directly at the ground and having a low variance of the vertical velocity component.

Details for the determination of $\mathrm{H} 1$ and just one lifted inversion $\mathrm{H} 2$ have been described in [7]. In extension to the method described in [5] the variance of the vertical velocity component is used here as a second variable in addition to the acoustic backscatter intensity. Acoustic remote sensing by a SODAR also yields wind fields that in principle could be used for determination of the mixing layer height, too. Because the wind information above the inversion is not regularly available from SODAR measurements, wind data have not been included into the scheme for the determination of the mixing layer height.

The height $\mathrm{H} 1$ corresponds to a sharp decrease of the acoustic backscatter intensity R(z) with height $\mathrm{z}$ usually indicating the top of a turbulent layer:

$$
\mathrm{H} 1=\mathrm{z} \text {, if }(\mathrm{R}(\mathrm{z})<88 \mathrm{~dB} \text { and } \mathrm{R}(\mathrm{z}+1)<86 \mathrm{~dB} \text { and } \mathrm{R}(\mathrm{z}+2)<84 \mathrm{~dB}) .
$$

The $\mathrm{dB}$ values are derived from an arbitrary scale because the received acoustic backscatter intensities from a SODAR cannot be calibrated. Therefore, the $\mathrm{R}(\mathrm{z})$ values are specific for the type of SODAR used. Therefore, the numbers in (8) can be taken for illustration purposes only.

Elevated inversions are diagnosed from secondary maxima of the backscatter intensity that are not related to high turbulence intensities. For elevated inversions increase in backscatter intensity below a certain height $\mathrm{z}=\mathrm{H} 2$ and a decrease above is stipulated while the turbulence intensity is low:

$$
\mathrm{H} 2 \_\mathrm{n}=\mathrm{z} \text {, if }\left(\partial \mathrm{R} /\left.\partial \mathrm{z}\right|_{\mathrm{z}+1}<0 \text { and } \partial \mathrm{R} /\left.\partial \mathrm{z}\right|_{\mathrm{z}-1}>0 \text { and } \sigma_{\mathrm{w}}<0.70 \mathrm{~ms}^{-1}\right)
$$

for $\mathrm{n}=1, \ldots, \mathrm{N}$. In [8] $\mathrm{N}$ was chosen to be five. Here, for the boundary-layer budget method, $\mathrm{N}=1$ is sufficient. The determination of the height of the stable surface layer $\mathrm{H} 3$ is started if the backscatter intensity in the lowest range gates is above $105 \mathrm{~dB}$ while $\sigma_{\mathrm{w}}$ is smaller than $0.3 \mathrm{~ms}^{-1}$. The top of the stable layer $\mathrm{H} 3$ is at the height where either the backscatter intensity sinks below $105 \mathrm{~dB}$ or $\sigma_{\mathrm{w}}$ increases above $0.3 \mathrm{~ms}^{-1}$.

$$
\begin{gathered}
\mathrm{H} 3=\mathrm{z}, \text { if }\left(\mathrm{R}(\mathrm{z})>105 \mathrm{~dB} \text { and } \mathrm{R}(\mathrm{z}+1)<105 \mathrm{~dB} \text { and } \sigma_{\mathrm{w}}(\mathrm{z})<0.3 \mathrm{~ms}^{-1}\right) \\
\text { or if }\left(\sigma_{\mathrm{w}}(\mathrm{z})<0.3 \mathrm{~ms}^{-1} \text { and } \sigma_{\mathrm{w}}(\mathrm{z}+1)>0.3 \mathrm{~ms}^{-1} \text { and } \mathrm{R}(\mathrm{z})>105 \mathrm{~dB}\right)
\end{gathered}
$$

The $\mathrm{dB}$ values in (10) are given for the same illustrative purpose as in (8). The search for $\mathrm{H} 1$ to $\mathrm{H} 3$ can be integrated into one search algorithm. If a surface-based stable layer with height $\mathrm{H} 3$ has been detected, the search for the first height $\mathrm{H} 2 \_1$ is started at the first range gate above H3, otherwise it starts at the lowest range gate. The search for elevated inversion is stopped when $\mathrm{N}$ elevated inversions have been found or the highest range gate of the available data has been reached.

The $\sigma_{\mathrm{w}}$ values used in (9) and (10) have been determined by optimizing the automatic application of the detection algorithm. In doing so it turned out that no lifted inversions occurred with a variance $\sigma_{\mathrm{w}}$ lower than $0.7 \mathrm{~ms}^{-1}$ and that the variance $\sigma_{\mathrm{w}}$ in nocturnal stable surface layers was below $0.3 \mathrm{~ms}^{-1}$. The first $\sigma_{\mathrm{w}}$ threshold made it possible to distinguish between inversions and elevated layers of enhanced turbulence. The latter $\sigma_{\mathrm{w}}$ threshold made it possible to differentiate between nocturnal stable surface layers and daytime super-adiabatic surface layers although both types of surface layers yield more or less the same level of backscatter intensity. Finally the mixing-layer or inversion height $\mathrm{z}$ from the acoustic remote sensing is determined as the minimum of $\mathrm{H} 1, \mathrm{H} 2 \_1$, and $\mathrm{H} 3$ :

$$
\mathrm{z}=\min \left(\mathrm{H} 1, \mathrm{H} 2 \_1, \mathrm{H} 3\right)
$$


An example for the application of (7) together with (11) is given here from data from a measurement campaign from 13 to 30 May 2003 which took place west of Munich, Germany. In contrast to [3] and [4], in the dataset used here the most important parameter in (7), the mixing-layer height $\mathrm{z}$, is known continuously from surface-based acoustic remote sensing with a sodar.

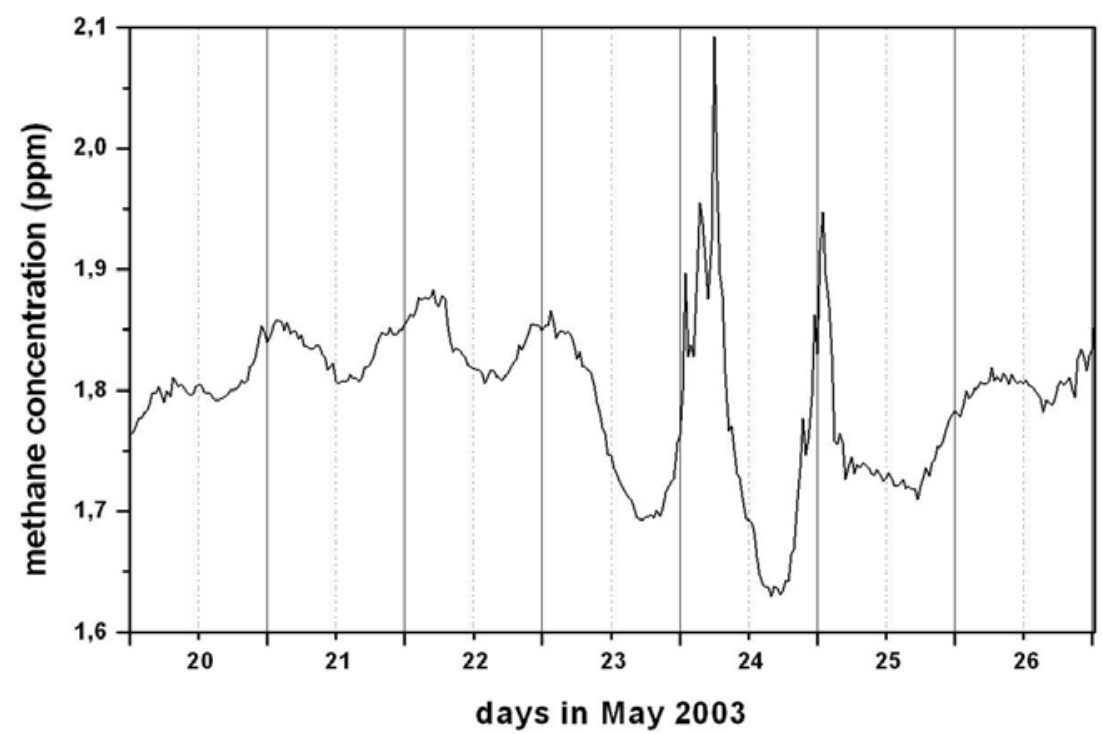

Figure 1. Variation of the near-surface concentration of methane (in ppm) in a rural area west of Munich during the week from May 20 to May 26, 2003.

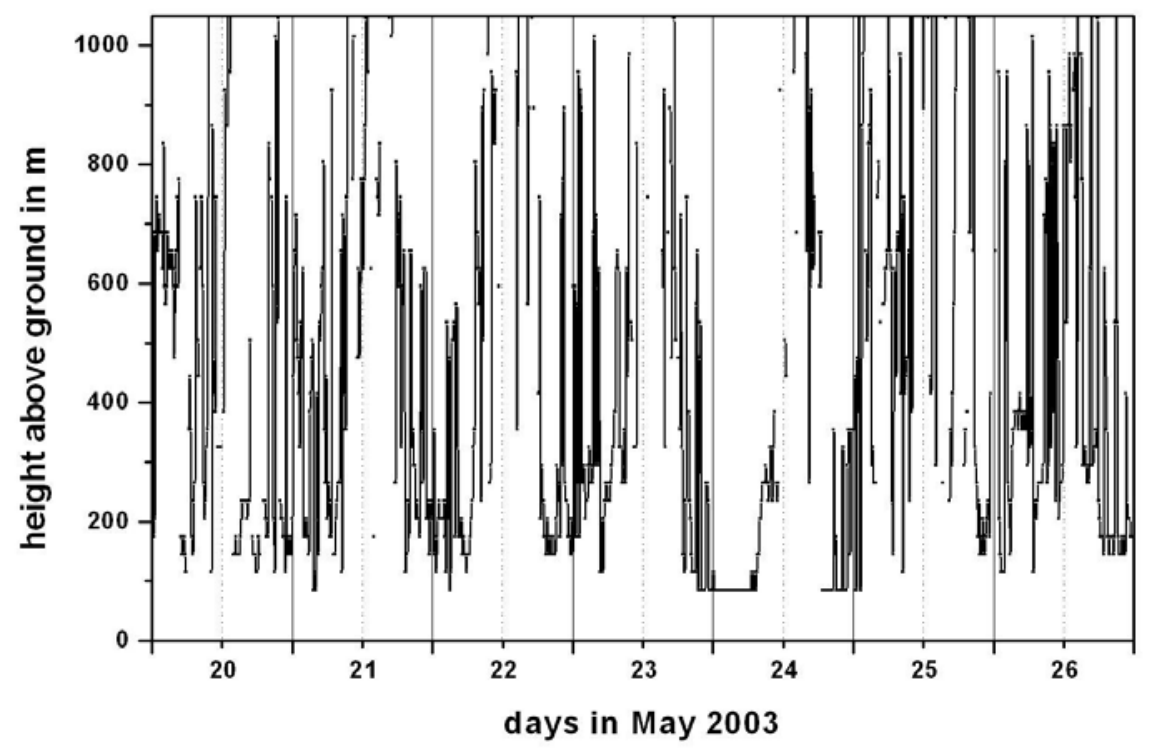

Figure 2. Fig. 1, but for the mixing-layer height derived from surface-based acoustic remote sensing (in $\mathrm{m}$ ). 
Fig. 1 shows a part of the time series of the near surface concentration of methane. It is remarkable in this time series that the concentration always increased in the evening and in the night and that it then decreased again during the next day. Apart from slightly changing wind speeds the depth of the nocturnal stable surface layer seems to be the most important factor controlling these concentration increases in the night. Fig. 2 displays the variation of the mixing layer height derived from sodar data (hourly values) for the same time period. In the nights to May 24 and 25 the mixing-layer heights took their lowest values and remained at these low values for six (May 25) to twelve (May 24) hours. Consequently the nocturnal increase was largest in these nights. Fig. 3 illustrates the overall correlation between the data shown in Figs. 1 and 2. There is a clear relation showing increasing methane concentrations with decreasing inversion height $z$ although the squared regression coefficient is low due to the large scatter of the data. Therefore, for the further analysis we will concentrate on the overall nocturnal increase of the methane concentration over eight hours (roughly from 10 p.m. to 6 a.m.) and compare this increase to the mean MLH for the same period.

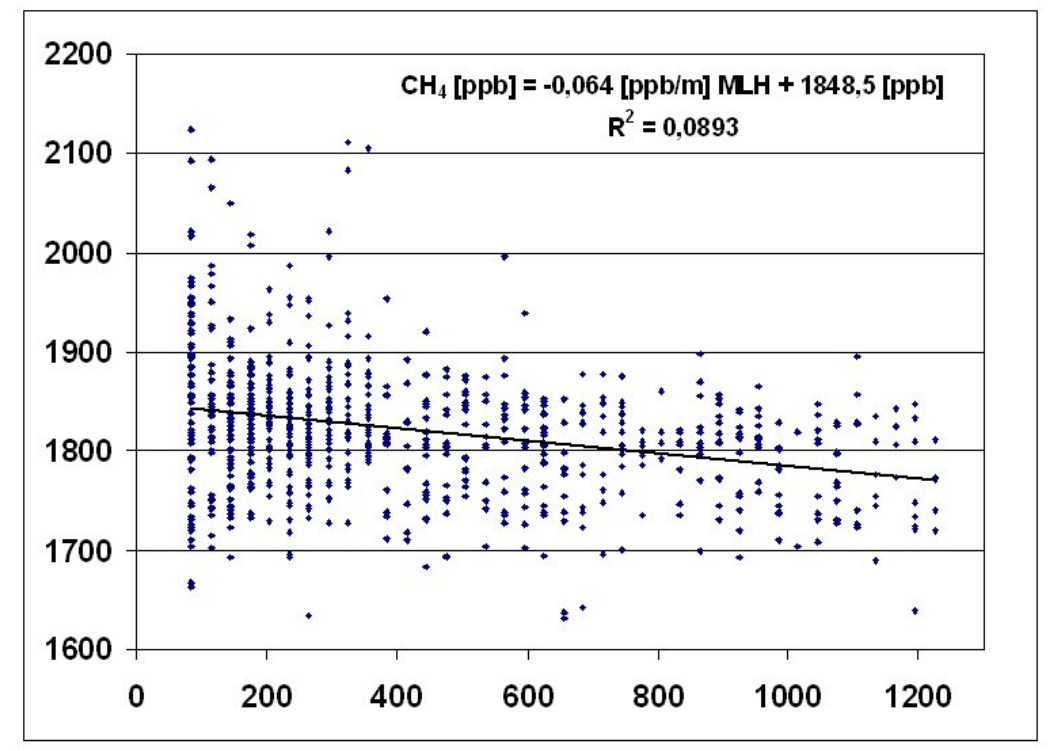

Figure 3. Overall correlation between the methane concentration and MLH based on half-hourly values for the period 10 May to 30 May 2003. A linear regression line is plotted and the equation for the regression line is given.

We now assume that the methane concentrations are equally dispersed within the shallow nocturnal boundary layer and that the measured mixing-layer height is representative for the region. We use (7) to convert the measured methane concentrations into spatially aggregated surface methane emission rates. The result is displayed in Fig. 4 for the whole measurement period of two weeks. A mean mixing-layer height for each night has been derived from the data shown in Fig. 2 and has been related to the mean nocturnal rate of increase in the methane concentration. The array of hyperbolae in Fig. 4 indicates emission rates which would explain the assumed correlation between the concentration increase and the mixing-layer height if the adopted conditions would last for about eight hours. It turns out that most data points lie between 0.1 and $1 \mu \mathrm{g} /\left(\mathrm{m}^{2} \mathrm{~s}\right)$. If one assumes that vertical mixing takes place within one hour (from the definition of the term mixing-layer adopted in [6]) then moderate horizontal winds of 3 to $5 \mathrm{~m} / \mathrm{s}$ would lead to horizontal transports of 11 to $18 \mathrm{~km}$ during this hour. From this estimation it can be inferred that emission rates calculated with this boundary-layer budget scheme are representative for an area of about 15 by $15 \mathrm{~km}^{2}$. 
The emission rate of 0.1 to $1 \mu \mathrm{g} /\left(\mathrm{m}^{2} \mathrm{~s}\right)$ can be compared to the total methane emissions in the Federal Republic of Germany which is $2.210^{18} \mu \mathrm{g}$ per year ([12]). Normalized to the area of $3.5710^{11}$ $\mathrm{m}^{2}$ this results in an average German methane emission rate of $0.2 \mu \mathrm{g} /\left(\mathrm{m}^{2} \mathrm{~s}\right)$. Two thirds of these emissions ([12]) are supposed to be from the agricultural sector (i.e. $0.13 \mu \mathrm{g} /\left(\mathrm{m}^{2} \mathrm{~s}\right.$ ). Since the measurements above have been made in a predominantly agricultural area, values a bit higher than the national average agricultural emission rate, as displayed in Fig. 4, can be regarded as realistic. On the other hand, incomplete vertical mixing in the nocturnal stable surface layer below the inversion would cause - under the assumptions used here - higher values emission values than the true value. Thus, some part of the higher emission rate found here could be due to incomplete vertical mixing. Seasonal variations in the methane emissions have been disregarded in this comparison.

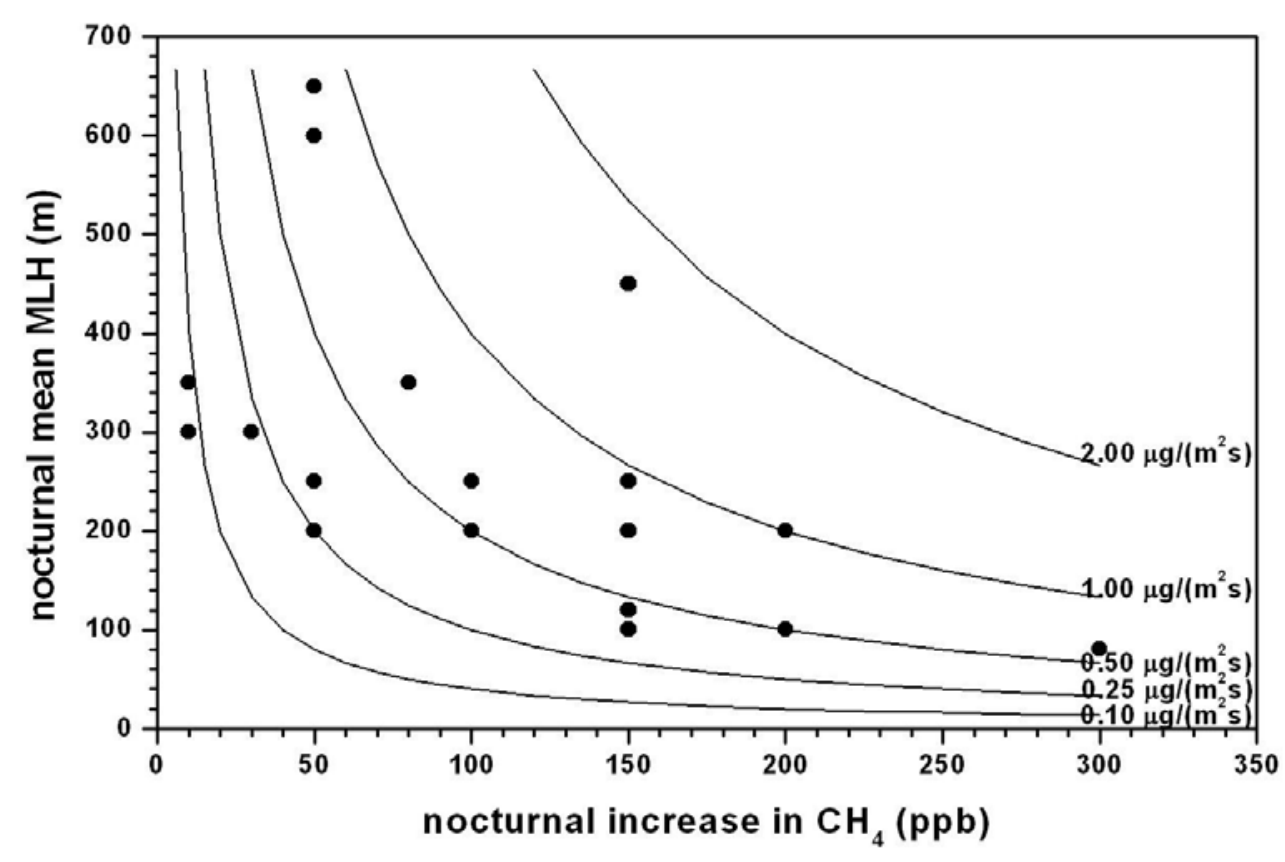

Figure 4. Correlation between the nocturnal increase of the near-surface methane concentration (x axis, in ppb) and the nocturnal mean mixing-layer height (y-axis, in $\mathrm{m}$ ) in a rural area west of Munich for 18 nights between May 13 and May 30, 2003 (dots). Curves give mean emission rates for constant conditions over about eight hours.

\section{Conclusions}

The feasibility of remote sensing to help to derive aggregated diffuse emission fluxes from larger areas has been demonstrated. In-situ measurements of such turbulent fluxes in the free atmosphere are difficult. Therefore other methods had to be developed to monitor turbulent fluxes. Naturally, these methods are indirect ones based on some sort of inversion algorithms. Here, a residual technique (or budget method) has been presented in chapters 2 and 3. Remote sensing of the mixing-layer height can deliver the most important parameter which is needed to apply successfully the nocturnal boundarylayer budget method addressed in chapter 3 .

The acoustic remote sensing technique alone is probably sufficient as long as the heights of nocturnal inversions have to be determined. If inversion or the mixing-layer heights during daytime 
are to be monitored the vertical range of a sodar can be insufficient, especially in spring and summer. In this case it is advisable to run a ceilometer in parallel to the sodar. The combined evaluation of both remote sensing devices can yield a quite complete picture of the vertical structure of the atmospheric boundary layer ([11]).

A good knowledge and a full understanding of the vertical turbulent fluxes in the atmosphere is a prerequisite for the assessment of air-surface exchange and regional and global energy budgets. In future, both the development of ground-based remote sensing and of budget methods has to be continued in order to further advance reliable weather and climate prediction techniques.

\section{Acknowledgements}

The measurements west of Munich have been made in the project ICAROS NET (IST-2000-29264) within the $5^{\text {th }}$ Framework Programme of the European Union.

\section{References}

[1] Schürmann G, Schäfer K,Jahn C, Hoffmann H, Groma V, Török S and Emeis S 2006 Airport air quality and emission studies by remote sensing and inverse dispersion modelling Proceedings of SPIE, Vol. 6362: Remote Sensing of Clouds and the Atmosphere XI, Slusser J $R$, Schäfer K, Comerón A, Editors, 63621E. (ISBN 0-8194-6457-0. ISSN 0277-786X. DOI: $10.1117 / 12.695821)$

[2] Schürmann G, Schäfer K, Jahn C, Hoffmann H, Bauerfeind M, Fleuti E and Rappenglück, B 2007 The impact of NOx, CO and VOC emissions on the air quality of Zurich airport Atmos. Environ. 41 103-18

[3] Denmead O T, Raupach M R, Dunin F X, Cleugh H A and Leuning R 1996 Boundary-layer budgets for regional estimates of scalar fluxes Global Change Biol. 2 255-64

[4] Denmead O T, Leuning R, Griffith D W T, Jamie I M, Esler M B, Harper L A and Freney J R 2000 Verifying inventory predictions of animal methane emissions with meteorological measurements Bound.-Lay. Meteorol. 96 187-209

[5] Beyrich F 1997 Mixing height estimation from sodar data - a critical discussion Atmos. Environ. 31 3941-53

[6] Seibert P, Beyrich F, Gryning S-E, Joffre S, Rasmussen A and Tercier P 2000 Review and intercomparison of operational methods for the determination of the mixing height Atmos. Environ. 34 1001-27

[7] Emeis S and Türk M 2004 Frequency distributions of the mixing height over an urban area from SODAR data Meteorol. Z. 13 361-67

[8] Emeis S, Jahn C, Münkel C, Münsterer C and Schäfer K 2007 Multiple atmospheric layering and mixing-layer height in the Inn valley observed by remote sensing Meteorol. Z. 16 415-24

[9] Emeis S and Schäfer K 2006 Remote sensing methods to investigate boundary-layer structures relevant to air pollution in cities Bound-Lay. Meteorol. 121 377-85

[10] Emeis S 2008 Examples for the determination of turbulent (sub-synoptic) fluxes with inverse methods Meteorol. Z. 17 3-11

[11] Schäfer, K., Emeis, S., Hoffmann, H., Jahn, C.: Influence of mixing layer height upon air pollution in urban and sub-urban area. Meteorol. Z. 15 (2006), 647-658.

[12] UBA 2007 Nationaler Inventarbericht zum Deutschen Treibhausgasinventar 1990-2005 Umweltbundesamt, Dessau. Schriftenreihe Climate Change 04/07 (ISSN 1862-4359), 538 pp. (available from http://www.umweltdaten.de/publikationen/fpdf-1/3239.pdf) 